INNOVATIONS IN PRIMARY CARE

\title{
Begin the Turn: A Mobile Recovery Program for a Targeted Urban Population
}

\author{
David T. O'Gurek, MD, FAAFP \\ Nicolle Strand, JD, MBE \\ Jonetta Gibbs, MS \\ Bryson Hoover-Hankerson \\ Victor Oluwafisayo Jegede \\ Ann Fam Med 2020;18:465. https://doi.org/10.1370/afm.2565.
}

\section{THE INNOVATION}

A mobile recovery unit staffed by a multidisciplinary team addresses addiction streetside in North Philadelphia, including treatment for opioid use disorder and a bridge to primary care services. The program was named Begin the Turn, playing on the vehicle making turns about the neighborhood as well as individuals beginning to turn from addiction. The Begin the Turn logo highlights the "BE U" letters within the name to designate the harm reduction approach to care.

\section{WHO \& WHERE}

The program serves a population streetside at 2 identified corners in the Kensington area of North Philadelphia, identified through mapping concentrated areas of fatal and nonfatal overdoses in this service area of the Temple University Health System. The population struggles with numerous physical and behavioral health challenges but notably struggles with high rates of homelessness.

\section{HOW}

The program's structure is based on the CeaseFire model, an initiative launched in Chicago in 1999 that uses prevention, intervention, and community-mobilization strategies (including credible outreach workers) to reduce gun violence. The goal of the program is to reduce the level of drug use, overdoses, and overdose deaths within targeted neighborhoods with high overdose death rates in Philadelphia, serving as a standard for community engagement around the overdose crisis. Services

Conflicts of interest: autbors report none

\section{CORRESPONDING AUTHOR}

David T. O'Gurek, MD, FAAFP

Department of Family \& Community Medicine

Lewis Katz School of Medicine at Temple University

1316 W Ontario Street

Philadelphia, PA 19140

david.ogurek@temple.edu are delivered through a mobile van that contains a clinical area, counseling area, waiting room, and bathroom.

A community board that oversaw program development ensured that the initiative remained community oriented and built systems that were both needed and desired by potential participants. The team consists of our program director/ lead physician, program coordinator, 3 outreach workers with relevant lived experience, our case manager, and 2 additional physicians. Our program coordinator is responsible for the overall, day-to-day operations including managing, motivating, and mentoring the team in a team-oriented environment. She also serves as behavioral health director who completes intakes on potential participants of the program which includes a social determinant of health and adverse childhood experience and trauma assessment. Our case manager, funded through a grant with the Commonwealth of Pennsylvania's Department of Human Services, works to address housing as well as other social, psychological, and medical needs. Outreach workers, as credible messengers within the community, assist with identifying people in need and aligning with behavioral health and case management to link patients to resources. Staff support, program administration, and the mobile unit was funded through state appropriations directed to Temple University for addiction outreach efforts. The program is closely aligned with Temple's TRUST Clinic and therefore benefits from options for pharmacy, transportation, housing, and food assistance.

\section{LEARNING}

Success of such a program relies on the building of a program that can bridge trust with the community to reduce the social exclusion and marginalization that individuals struggling with both homelessness and substance use disorder (SUD) face. ${ }^{1}$ While early frustrations led to significant delays in obtaining a mobile unit and having the necessary service arrangements, these delays enabled the outreach workers to obtain a significant amount of early data on the characteristics of the population including demographics and social needs. Among all those engaged in this early process, $83 \%$ were interested in buprenorphine treatment and information regarding their specific social needs enabled the program to more directly align with services as well as design a program uniquely fitted to meet the needs of individuals we would be serving.

Additional information, including affiliations, references, key words, funding info, previous presentations, and submitted dates are online at https://www.AnnFamMed.org/content/18/5/465. 